\title{
CRISPR-Cas orthologues and variants: optimizing the repertoire, specificity and delivery of genome engineering tools
}

\author{
Alberto Cebrian-Serrano $^{1} \cdot{\text { Benjamin } \text { Davies }^{1}}^{(\mathbb{D}}$
}

Received: 1 February 2017 / Accepted: 26 May 2017 / Published online: 20 June 2017

(c) The Author(s) 2017. This article is an open access publication

\begin{abstract}
Robust and cost-effective genome editing in a diverse array of cells and model organisms is now possible thanks to the discovery of the RNA-guided endonucleases of the CRISPR-Cas system. The commonly used Cas9 of Streptococcus pyogenes shows high levels of activity but, depending on the application, has been associated with some shortcomings. Firstly, the enzyme has been shown to cause mutagenesis at genomic sequences resembling the target sequence. Secondly, the stringent requirement for a specific motif adjacent to the selected target site can limit the target range of this enzyme. Lastly, the physical size of Cas 9 challenges the efficient delivery of genomic engineering tools based on this enzyme as viral particles for potential therapeutic applications. Related and parallel strategies have been employed to address these issues. Taking advantage of the wealth of structural information that is becoming available for CRISPR-Cas effector proteins, Cas9 has been redesigned by mutagenizing key residues contributing to activity and target recognition. The protein has also been shortened and redesigned into component subunits in an attempt to facilitate its efficient delivery. Furthermore, the CRISPR-Cas toolbox has been expanded by exploring the properties of Cas9 orthologues and other related effector proteins from diverse bacterial species, some of which exhibit different target site specificities and reduced molecular size. It is hoped that the improvements in accuracy, target range and efficiency of delivery will facilitate the therapeutic application of these site-specific nucleases.
\end{abstract}

Benjamin Davies

ben.davies@well.ox.ac.uk

1 Wellcome Trust Centre for Human Genetics, University of Oxford, Oxford OX3 7BN, UK

\section{Introduction}

The discovery and application of Clustered Regularly Interspaced Short Palindromic Repeats (CRISPR) and CRISPR-associated (Cas) systems for genetic modification have revolutionized biomedical research in just a few years. The CRISPR-Cas9 system has proven itself to be a robust genome editing tool in mammalian cells and animal models, and has rapidly shown its great potential in diverse fields such as functional genomics, genome-wide screening studies, therapeutic gene therapy and agricultural applications. The technology based on CRISPR-Cas9 has surpassed other nucleases that preceded it, such as the zinc finger nucleases (ZFNs) and transcription-activatorlike effector nucleases (TALENs) in terms of simplicity, efficiency and amenability to multiplexing, becoming the most broadly implemented approach for genome engineering today.

CRISPR-Cas systems are natural RNA-guided adaptive immune systems of bacteria and archaea that provide sequence-specific resistance against viruses or other invading genetic material. This immune-like response has been divided into two classes on the basis of the architecture of the effector module responsible for target recognition and the cleavage of the invading nucleic acid (Makarova et al. 2015). Class 1 comprises multi-subunit Cas protein effectors and Class 2 consists of a single large effector protein. Both Class 1 and 2 use CRISPR RNAs (crRNAs) to guide a Cas nuclease component to its target site where it cleaves the invading nucleic acids. Due to their simplicity, Class 2 CRISPR-Cas systems are the most studied and widely applied for genome editing. 


\section{CRISPR-Cas9 system}

Cas9, the nuclease, is active when it forms a complex with two naturally occurring RNA species, the tracrRNA and the crRNA (Jinek et al. 2012). The first 20 nucleotides of the crRNA sequence define the specificity of the nuclease, which occurs by complementary base pairing with the target sequence within genomic DNA. Once activated, the nuclease generates a double-strand break (DSB) at the target site. Cas9 uses two distinct active sites, RuvC and $\mathrm{HNH}$, generating site-specific nicks on opposite DNA strands (Gasiunas et al. 2012; Jinek et al. 2012). By simply specifying the targeting sequence of the crRNA, one can direct the CRISPR-Cas9 system to the appropriate genomic target site. An additional requirement for Cas9-mediated genome cleavage is the presence of a short and conserved protospacer adjacent motif (PAM) flanking the genomic target site. Functionality in mammalian cells was rapidly demonstrated and the native bacterial system was further simplified into a two-component system, with the crRNA and tracrRNA fused together to form a single-guide RNA (sgRNA) (Cho et al. 2013; Cong et al. 2013; Jinek et al. 2013; Mali et al. 2013a).

CRISPR-Cas9 systems promote genome editing by inducing a DSB at a target genomic loci, which is quickly acted upon by the cell's DNA repair machinery. The generated ends of DNA can be religated by non-homologous end joining (NHEJ), a process known to be quite precise (Bétermier et al. 2014) but which can also introduce indel mutations at the DSB site (Lieber 2010), especially when the nucleases are active in the cell for a prolonged period. Alternatively, regions of homology flanking the DSB can lead to a process known as microhomology mediated end joining (MMEJ), also introducing indel mutations at the target site (Sinha et al. 2017). These indel mutations provide a means of disrupting protein coding or other functional DNA sequences. An additional pathway, homology directed repairs (HDR), can be adopted by the cell to repair the lesion accurately if homologous DNA sequences are present (Greene 2016). The HDR repair pathway enables intentional replacement of endogenous genomic sequence with information on a homologous donor molecule, presented to the cell. These templates can be delivered as single stranded oligodeoxynucleotide (ssODN) harbouring desired nucleotide changes (Cong et al. 2013) or as conventional double-stranded DNA targeting constructs (Chu et al. 2016), in both cases with regions of homologous sequence flanking the sequence change.

Among the different bacteria harbouring CRISPR-Cas systems, the human pathogen Streptococcus pyogenes was one of the first bacteria in which CRISPR type II loci were characterized (Deltcheva et al. 2011). Furthermore, it was SpCas9 that was first used to cleave and edit a specific region of the genome of a human cell (Cho et al. 2013; Cong et al. 2013; Jinek et al. 2013; Mali et al. 2013a). In the following months, many groups applied SpCas9-mediated genome editing successfully across a broad range of animal models, including yeast, nematode, fruit fly, zebrafish, mouse, pig, rabbit and monkey (reviewed by Sander and Joung 2014).

\section{SpCas9 modification: SpCas9 nickase}

Despite the simplicity and high levels of mutagenesis reported with SpCas9, concerns about specificity were quickly raised; it was found that the crRNA could tolerate certain mismatches to the DNA target and could cleave and thus mutagenize the genome at these mismatched sequences-so-called off-targets (Cradick et al. 2013; Fu et al. 2013). Although the real importance of off-target effects is still under study (Iyer et al. 2015), these specificity limitations would clearly complicate potential therapeutic applications and produce a source of variability in biological studies. With the objective of reducing potential off-target effects without decreasing efficiencies, Cas9 variants were developed which had each of the two nuclease domains silenced by a point mutation of a key catalytic residue (D10A for HNH and H840A for RuvC) (Fig. 1a; Table 1) (Cong et al. 2013; Mali et al. 2013b; Ran et al. 2013). These so-called nickases (nSpCas9) retained the specificity of action but only cleaved a single strand of the DNA. This approach benefits from the fact that individual nicks in the genome are repaired with high fidelity (Dianov and Hübscher 2013), while nicking of both DNA strands by a pair of opposite orientated Cas9 nickases in close proximity would lead to a DSB that would then be processed by the NHEJ or HDR activities of the cell. Although this approach clearly reduces the number of possible target sites available within the genome, the method has been used successfully to facilitate efficient genome engineering with minimal off-target effects in mammalian cells and mouse zygotes (Cho et al. 2014; Cong et al. 2013; Ran et al. 2013; Shen et al. 2014).

Using paired nSpCas9 to induce large deletions, up to $1 \mathrm{~kb}$ deletions have been reported in human cells without observing unwanted translocations (Cho et al. 2014). More recently, efficient bi-allelic targeting of a silent locus and a single nucleotide substitution has been described using nSpCas9 in patient derived induced pluripotent stem (iPS) cells (Eggenschwiler et al. 2016) and fibroblasts (Osborn et al. 2015). Also in human iPS cells, Wu et al. reported a GFP insertion by nSpCas9 (Wu et al. 2016). Addressing an episomal target, nSpCas9 was used successfully to target multiple Hepatitis B virus closed circular DNA in HepG2 cells without apparent off-target mutations (Sakuma et al. 

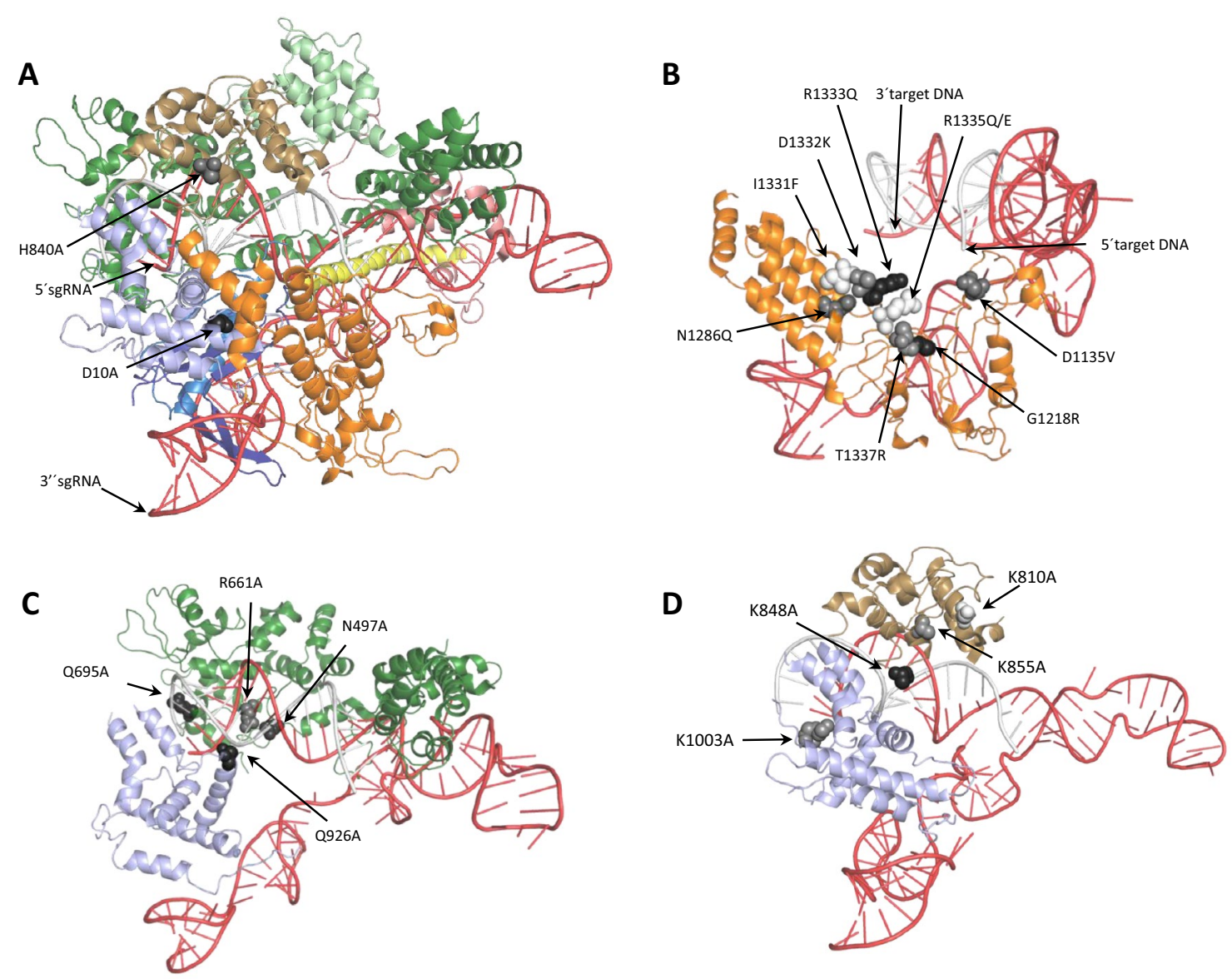

Fig. 1 Position of mutagenized residues in SpCas9. a Crystal structure of SpCas9 in complex with sgRNA and target DNA (PDB ID 4OO8). The position of the catalytic residues responsible for the $\mathrm{HNH}$ (Asp-10) and the RuvC (His-840) nuclease activity, which are mutated in the D10A and H840A nickases, are shown in black and grey respectively. b Detail of the PAM interaction domain in complex with guide RNA and target DNA showing the position of the key residues mutated in variant Cas9 with altered PAM specificities and how

2016). In two studies performed in vivo in mouse zygotes, knock-in manipulations, generating a floxed allele (Lee and Lloyd 2014) and a single nucleotide substitution (Mianné et al. 2016), were successfully performed by the injection of nSpCas9 as mRNA with paired sgRNA guides and ssODN donor templates.

Side-by-side analysis of mutation efficiencies using either wild-type SpCas9 or a paired nickase have revealed conflicting results. An initial study reported higher activity for the wild-type enzyme than the nickase on a mutant eGFP gene (Bialk et al. 2015), although whether this result would hold up across many different loci in unclear. In a further comparison, oncogenic chromosome translocations were induced by either wild-type SpCas9 enzymes or paired $\mathrm{nSpCas} 9$ combinations with lower translocation frequency reported for paired nSpCas9 (Ghezraoui et al.

they are mutated. c and $\mathbf{d}$ Detail of the target interaction domain in complex with guide RNA and target DNA showing the position of the key residues mutated in SpCas9-HF1 (c) and eSpCas9 (d) and how they are mutated. Residue Arg-1060, mutated in eSpCas9 (1.0) and (1.1), is not annotated in the crystal structure. The $20 \mathrm{bp}$ target DNA is shown in white and the sgRNA is shown in red. (Color figure online)

2014). In the results, the deletions observed at the translocation junctions generated with $\mathrm{nSpCas} 9$ were significantly longer than those generated from wild-type Cas9, presumably due to processing of large overhangs generated by the nickase enzyme. With the aim to characterize HDR/NHEJ ratios, a comparison between single and dual nSpCas9 systems found that single, dual and tandem (Cas9-D10A plus Cas9-H840A) nSpCas9 can induce more HDR than NHEJ in HEK293 cells (Miyaoka et al. 2016). In agreement, nCas9 was found to promote HDR and minimize NHEJ in a traffic light reporter assessment of DNA repair fates in this same cell type (Osborn et al. 2015). Potentially, this might also be due to the staggered overhangs which inevitably occur following the action of paired nickases which are considered to be more recombinogenic than the blunt ends generated by the wild-type Cas9. Future work must 


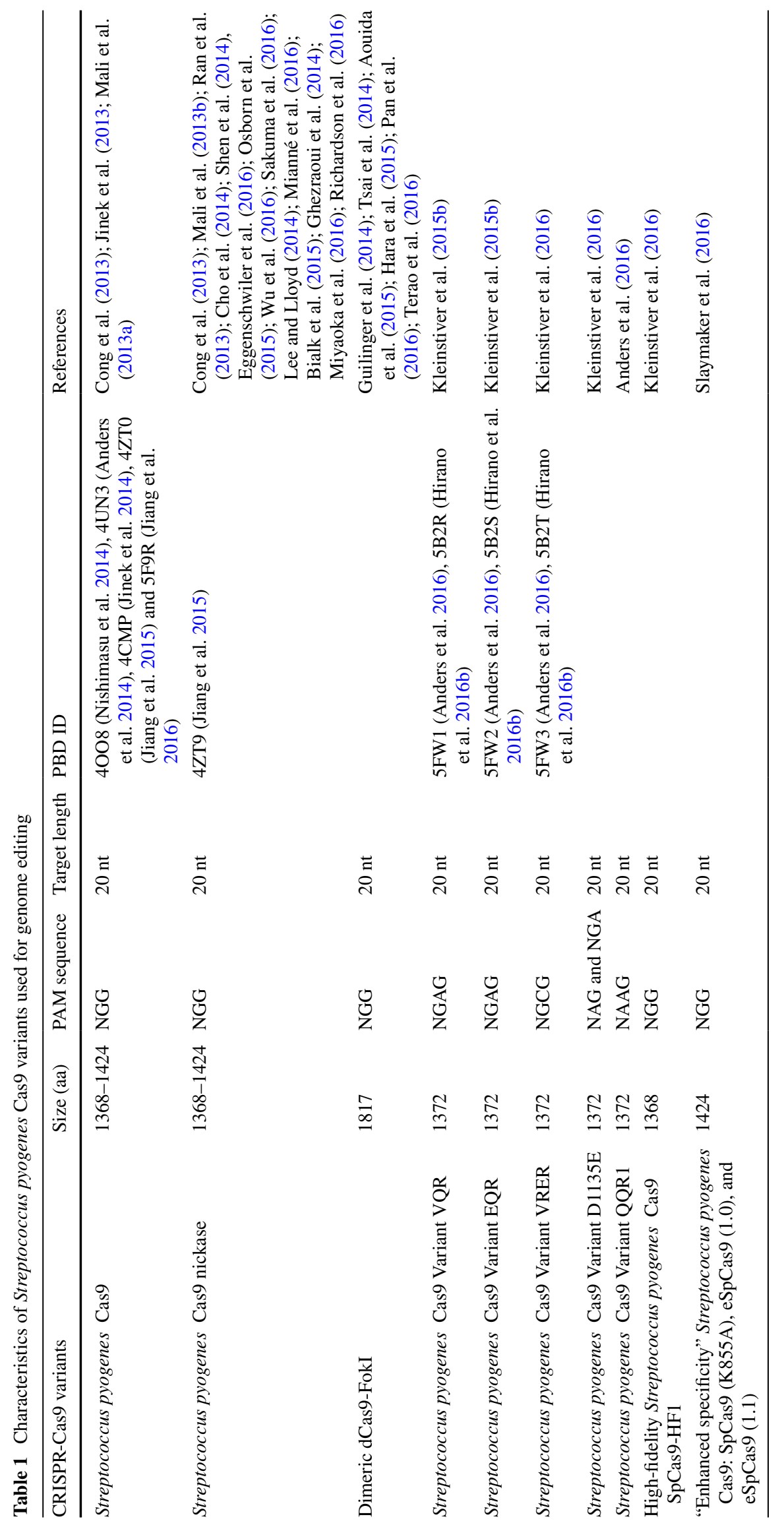


examine whether these observations hold true across multiple genomic loci and cell types and the analysis of knock-in efficiencies might cast light on how the overhangs can be designed to enhance HDR repair.

Recently, concerns about the use of paired Cas9 nickase for genome editing has been raised (Richardson et al. 2016). Using single nickase ribonucleoprotein electroporation, single nicks induced by either Cas9-D10A or Cas9H840A were able to stimulate HDR $(\sim 10 \%)$ in cells when provided with the ssDNA, and also silenced a BFP reporter gene, probably by inducing error-prone NHEJ. Similarly, single nicks have been shown to promote efficient HDR via an alternative HDR pathway (Davis and Maizels 2014), with little accompanying mutagenic end joining observed, which is of course ideal for genome engineering applications. It is as yet unclear how universal these phenomena are, and it is becoming clear that both the cell type and the delivery route of the nuclease or nickase may play an important role in determining repair outcome (Kim et al. 2014). Certainly, the suggestion that single nicks can be recombinogenic undermines the argument that these lesions within the genome are accurately repaired, thus questioning the validity of the paired nickase approach for reducing off-target mutagenesis.

\section{FokI-fused catalytically inactive Cas9}

One of the main differences between ZFNs and TALENs endonucleases and CRISPR-Cas based system concerns specificity and this is clearly a result of its mechanism of action. As previously discussed, Cas9 is a monomeric nuclease which acts when coupled to its guiding sgRNA to produce a DSB at its target site. In contrast, the nuclease domain of ZFNs and TALENs requires dimerization for activity and subsequently these dimeric nucleases cleave DNA only when two simultaneous, adjacent monomerbinding events take place. The likelihood of dimeric offtarget binding events is considerably smaller than the likelihood of a monomeric off-target binding event and thus specificity is markedly improved. With these principles in mind, SpCas9 has been adapted to a dimeric nuclease with a similar mode of binding, potentially matching the specificities of ZFNs and TALENs, although similar to the double nickase approach, the number of potential genomic target sites for these Fok1-dimeric nucleases is reduced. SpCas9 was rendered catalytically inert by mutation of both nuclease domains, creating what is known as a "deadCas9" (dCas9) which was then fused to the Fok1 nuclease domain (fCas9) (Aouida et al. 2015; Guilinger et al. 2014; Tsai et al. 2014). Functionality of this enzyme in achieving mutagenesis of target sites in human cells was demonstrated and these reports also confirmed the specificity of the approach-cleavage activity of fCas9 depends on the simultaneous binding of two guide sgRNAs to their genomic DNA targets with a defined spacing and orientation (15-25 base pairs apart). The fCas9 approach was used to correct the phenylalanine hydroxylase gene in COS-7 cells (Pan et al. 2016). fCas9 has also been shown to be suitable for the generation of knockout mice by microinjection of zygotes with fCas9 mRNA and two sgRNAs spaced 14-19 bases apart (Hara et al. 2015). This study reported similar genome editing efficiencies than those observed using wild-type SpCas9 and nSpCas9. To further simplify the production of mutant mice, genetically modified mice were obtained using chemically synthesized crRNA and tracrRNA plus nSpCas9 or fCas 9 by microinjection into fertilized eggs (Terao et al. 2016). A side-by-side comparison using fCas9, nSpCas9 and wild-type SpCas9 to target six human genes showed average indel frequencies of 14.9, 20.6 and $28.2 \%$, respectively (Guilinger et al. 2014), suggesting a drop in efficiency with these Cas9 variants.

\section{Engineered Cas9 variants with novel PAM specificities}

One of the key factors that determine CRISPR-Cas specificity is the nature of the PAM sequence. In the case of SpCas9, a DSB is produced when a NGG sequence (canonical PAM) lies immediately $3^{\prime}$ of the target DNA sequence. However, it has been reported that alternative PAM sequences ( $3^{\prime} \mathrm{NAG}$ and NGA) can, to an extent, be recognized by the SpCas9-sgRNA complex (Kleinstiver et al. 2015b; Zhang et al. 2014), potentially increasing the likelihood of off-target mutagenesis. The requirement for a 3' NGG PAM is, however, considered quite stringent and, depending on the primary sequence of DNA, this might limit the sequences that can be addressed, particularly in A/T-rich regions of the genome. One potential solution to address targeting range limitations would be to engineer Cas9 variants with novel PAM specificities. Kleinstiver et al. explored the possibility of rendering SpCas9 sensitive to alternative PAM sequences by introducing mutations into the PAM-interacting domains of wild-type SpCas9 (Kleinstiver et al. 2015b). SpCas9 variants were successfully engineered which recognize NGCG (variant VRER, D1135V/G1218R/R1335E/T1337R), NGAG (variant VQR, D1135V/R1335Q/T1337R) or NGAG (variant EQR, D1135E/R1335Q/T1337R) (Fig. 1b; Table 1), previously inaccessible sites, and these enzymes showed similar (or better) genome-wide specificities compared to wild-type SpCas9 in human cells and zebrafish embryos. In addition, a D1135E mutation in SpCas9 was found to improve the PAM recognition and specificity of SpCas9, decreasing off-target mutagenesis with non-canonical NAG and NGA 
PAMs and/or mismatched target sites. A NAAG specific SpCas9 variant (variant QQR1, G1218R/N1286Q/I1331F/ D1332K/R1333Q/R1335Q/T1337R) (Fig. 1b; Table 1) was engineered and tested in vitro, revealing a slower cleavage activity than that of wild-type SpCas9 (Anders et al. 2016).

\section{DNA-binding domain fusions}

Cas9 has also been fused to other programmable DNAbinding domains, such as Zinc Finger binding domains and TALE domains, designed against sequences lying downstream of the Cas9 target site. By tethering the Cas9 in this sequence-specific manner, the requirement for the $3^{\prime}$ NGG PAM was partially overcome and cleavage of alternative PAM sequences was achieved (Bolukbasi et al. 2015). The same study combined this tethering idea with Cas9 mutations that compromised the key PAM recognition residues (Arg1333 and Arg1335). These attenuated Cas9-programmable DNA-binding domain (Cas9-pDBD) nucleases showed improved precision as judged by deep sequencing of previously characterized off-target sites for 3 genomic target sites. An unbiased assessment of off-target mutagenesis also revealed no new sites are generated by the Cas9pDBD fusions (Bolukbasi et al. 2015).

\section{Engineering enzymes with increased fidelity- SpCas9-HF1/eSpCas9}

Application of genome engineering in biomedicine is a major challenge and for successful clinical use, off-target mutagenesis needs to be eliminated on a genome-wide scale. One recently explored approach raised the idea of redesigning the DNA-binding domain of SpCas9 to reduce non-specific DNA contacts, thus increasing specificity. Studies of the crystal structure of SpCas9-sgRNA-target DNA complex have concluded that the SpCas9-sgRNA complex might possess more energy than is needed for optimal recognition of its intended target DNA site, which might then be responsible for off-target binding activity (Kleinstiver et al. 2016; Slaymaker et al. 2016). With this hypothesis in mind, 15 SpCas9 variants with residue substitutions in positions that form hydrogen bonds with the DNA backbone were constructed and the variant enzymes characterized for on and off-target activity (Kleinstiver et al. 2016). One of the SpCas9 variants with four residues substitution showed similar on-target efficiency, with at least $70 \%$ of the activity observed with native SpCas9, but exhibited considerably higher genome-wide specificity (SpCas9HF1, N497A/R661A/Q695A/Q926A) (Fig. 1c; Table 1), reducing nearly all genome-wide off-target effects to near undetectable levels. In addition, this study demonstrated that the introduction of substitutions at other non-specific DNA contacting residues into the SpCas9-HF1 protein (similar to the above mentioned D1135E mutation) could further reduce some of the residual off-target activity that prevail for certain sgRNAs. In a complementary approach, Slaymaker et al. suggested that positively charged residues positioned between the $\mathrm{HNH}$, RuvC, and PAM-interacting domains in SpCas9, in the so-called non-target strand groove, are involved in stabilizing the non-target strand of the target DNA (Slaymaker et al. 2016). Thus, a way to reduce the energy of the non-target strand binding would be to neutralize the positive charges positioned in this groove. After the characterization of 31 SpCas9 mutants, three were identified with similar efficiency than wild-type SpCas9 (SpCas9-K855A, eSpCas9 [1.1] [K848A/K1003A/ R1060A] and eSpCas9 [1.0] [K810A/K1003A/R1060A]) (Fig. 1d; Table 1). The off-target assessment showed that two of the variants, SpCas9-K855A and eSpCas9 (1.1), exhibited a genome-wide reduction in off-target cleavage without generating any new off-target sites. Both studies (Kleinstiver et al. 2016; Slaymaker et al. 2016) reinforce the idea that mutations designed to weaken interactions in the SpCas9-sgRNA-target DNA complex can lead to a considerable improvement in specificity. It will be interesting to see whether, when applied in a variety of different experimental settings, the activity of these engineered enzymes at their designated targets matches that of the unmodified enzyme at all genomic target sites.

Modifications in the sgRNA may also increase the target specificity of the CRISPR-Cas9 system. A simple strategy of truncating the sgRNA sequence at the $5^{\prime}$ end with shorter regions of target complementarity has been reported with a reduction of off-target mutagenesis at some loci (Fu et al. 2014). As an alternative approach, the addition of two extra guanine nucleotides at the $5^{\prime}$ end of sgRNA has been shown as a factor that can affect mutation frequencies both onand off-target (Cho et al. 2014). This manipulation of the sgRNA, advantageous for their efficient transcription by the T7 polymerase, was shown to decrease off-target site cleavage substantially (Kim et al. 2014; Kim et al. 2015). However, lower on-target mutagenesis efficiency was reported for certain target sites (Cho et al. 2014).

\section{Therapeutic delivery: size constraints}

In addition to accuracy, for a realistic chance of applying genome editing tools in a therapeutic context, an efficient delivery mechanism must be assured. Adeno-associated virus (AAV) vectors are one of the most widely used delivery mechanisms for gene therapy (Naldini 2015). However, the cargo size of AAV (around $4.7 \mathrm{~kb}$ ) is a limitation for 
packaging the SpCas9 $(4.2 \mathrm{~kb})$ and its promoter driven sgRNA in an "all in one" vector.

Structural studies of SpCas9 revealed a potential redundancy with the recognition lobe of the protein and thus a candidate region for shortening the protein, facilitating its therapeutic delivery. A deletion mutant $(\Delta 175-307)$ was generated which did indeed retain nuclease activity, however overall activity was reduced by half which was a considerable price to pay for a saving of only 133 amino acids (Nishimasu et al. 2014). An alternative strategy for reducing the size of SpCas9 involved the separation of the recognition lobe from the nuclease lobe into two separate vectors. When used in combination with the sgRNA, a functional CRISPR-Cas9 nuclease was reconstituted, although activity as measured by indel mutagenesis in mammalian cells was reduced compared to the native enzyme (Wright et al. 2015). A similar split Cas9 approach, which used a dimerization domain to facilitate enzyme reconstitution, demonstrated similar functionality but also reported lower rates of mutagenesis (Zetsche et al. 2015b). Trans protein splicing using the intein-extein system provided a more robust solution of delivering, effectively, the native enzyme, with the two lobes of SpCas9 encoded on separate vectors (Truong et al. 2015). Indeed, successful packaging into recombinant $\mathrm{AAV}$ and delivery into cells in vitro was shown to achieve mutagenesis. Interestingly, there was sufficient capacity within the two recombinant viruses to include a homology template. Thus, delivery of site-specific nucleases together with a therapeutic template could be achieved in two modestly sized viral vectors.

\section{Cas9 orthologues}

Another route to solving the delivery problem of the CRISPR-Cas9 components is to consider alternative CRISPR effectors from other bacterial and archeal species which are smaller in size (Fig. 2). Indeed, orthologous enzymes from other bacteria have been investigated and applied in mammalian systems, including the mouse zygote (Table 2). Interesting, as explored below, these orthologous enzymes show different substrate specificities, frequently recognizing a different length of target sequence and a different PAM. Thus, the use of Cas9 orthologues or other

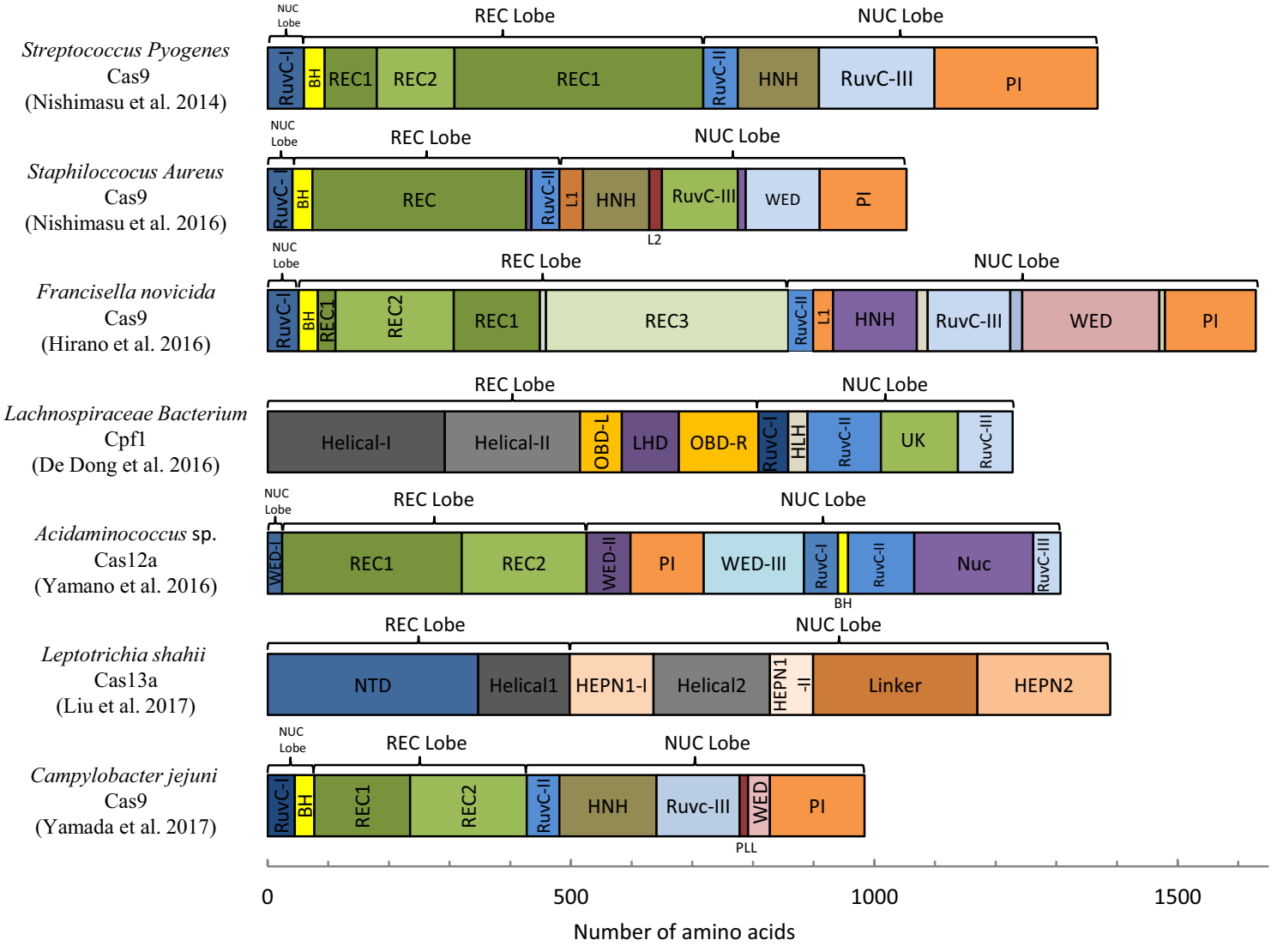

Fig. 2 Domain structure of CRISPR-Cas effector orthologues. REC recognition domain, $N U C$ Nuclease domain, PI PAM interaction domain, $B H$ bridge helix domain, $L 1$ and $L 2$ linker 1 and 2, WED wedge domain, $O B D$ oligonucleotide-binding domain, $L H D$ loopedout helical domain, $U K$ Unknown function domain, NTD N-terminal domain, $P L L$ phosphate lock loop 
Table 2 Characteristics of CRISPR-Cas effector orthologues used for genome editing

\begin{tabular}{|c|c|c|c|c|c|c|c|}
\hline $\begin{array}{l}\text { Species and effec- } \\
\text { tors }\end{array}$ & Class and type & Size (aa) & PAM sequence & Target length & PBD ID & $\begin{array}{l}\text { Cell line/organ- } \\
\text { ism targeted }\end{array}$ & References \\
\hline \multirow[t]{5}{*}{$\begin{array}{l}\text { Staphylococcus } \\
\text { aureus } \text { Cas } 9\end{array}$} & \multirow[t]{7}{*}{ Class II type II } & \multirow[t]{5}{*}{1,053} & \multirow[t]{5}{*}{ NNGRRT } & \multirow[t]{5}{*}{20 to $24 \mathrm{nt}$} & \multirow[t]{5}{*}{$\begin{array}{l}\text { 5AXW and 5CZZ } \\
\text { (Nishimasu } \\
\text { et al. 2015) }\end{array}$} & $\begin{array}{l}\text { Human cells and } \\
\text { mice (in vivo } \\
\text { delivered by } \\
\text { AAV delivery) }\end{array}$ & Ran et al. (2015) \\
\hline & & & & & & Mouse zygotes & Zhang et al. (2016) \\
\hline & & & & & & $\begin{array}{l}\text { Mouse (in vivo } \\
\text { delivered by } \\
\text { AAV) }\end{array}$ & $\begin{array}{l}\text { Kaminski et al. } \\
\text { (2016) }\end{array}$ \\
\hline & & & & & & $\begin{array}{l}\text { Human hemat- } \\
\text { opoietic stem } \\
\text { and progenitor } \\
\text { cells }\end{array}$ & Ye et al. (2016) \\
\hline & & & & & & HEK293FT cells & $\begin{array}{l}\text { Nishimasu et al. } \\
\text { (2015) }\end{array}$ \\
\hline $\begin{array}{l}\text { Staphylococcus } \\
\text { aureus Cas9 } \\
\text { Nickase }\end{array}$ & & 1,053 & NNGRRT & $24 \mathrm{nt}$ & & HEK293T cells & $\begin{array}{l}\text { Friedland et al. } \\
\text { (2015) }\end{array}$ \\
\hline $\begin{array}{c}\text { Staphylococcus } \\
\text { aureus } \mathrm{KKH} \\
\text { Cas9 variant }\end{array}$ & & 1,053 & NNNRRT & $21 \mathrm{nt}$ & & U2OS cells & $\begin{array}{l}\text { Kleinstiver et al. } \\
\text { (2015a) }\end{array}$ \\
\hline \multirow{4}{*}{$\begin{array}{l}\text { Streptococcus } \\
\text { thermophilus1 } \\
\text { Cas9 }\end{array}$} & \multirow[t]{4}{*}{ Class II type II } & \multirow[t]{4}{*}{1,122} & \multirow[t]{4}{*}{ NNAGAAW } & \multirow[t]{4}{*}{19 to $20 \mathrm{nt}$} & & HEK293FT cells & Cong et al. (2013) \\
\hline & & & & & & HEK293T cells & Esvelt et al. (2013) \\
\hline & & & & & & Mouse zygotes & Fujii et al. (2016) \\
\hline & & & & & & HEK293T cells & Muller et al. (2016) \\
\hline \multirow{3}{*}{$\begin{array}{l}\text { Streptococcus } \\
\text { thermophilus } 3 \\
\text { Cas9 }\end{array}$} & \multirow[t]{3}{*}{ Class II type II } & \multirow[t]{3}{*}{1,393} & \multirow[t]{3}{*}{ NGGNG } & \multirow[t]{3}{*}{$19 \mathrm{nt}$} & & HEK293T cells & Xu et al. (2015) \\
\hline & & & & & & HEK293T cells & Muller et al. (2016) \\
\hline & & & & & & HEK293T cells & $\begin{array}{l}\text { Glemzaite et al. } \\
\text { (2015) }\end{array}$ \\
\hline \multirow[t]{3}{*}{$\begin{array}{l}\text { Neisseria menin- } \\
\text { gitidis Cas9 }\end{array}$} & \multirow[t]{3}{*}{ Class II type II } & \multirow[t]{3}{*}{1,109} & \multirow[t]{3}{*}{ NNNNGATT } & \multirow[t]{3}{*}{$23,24 \mathrm{nt}$} & & $\begin{array}{l}\text { Human induced } \\
\text { pluripotent stem } \\
\text { and HEK293FT } \\
\text { cells }\end{array}$ & Hou et al. (2013) \\
\hline & & & & & & HEK293T cells & Esvelt et al. (2013) \\
\hline & & & & & & HEK293T cells & Lee et al. (2016) \\
\hline $\begin{array}{l}\text { Francisella novi- } \\
\text { cida Cas9 }\end{array}$ & Class II type II & 1,629 & NGG & $22 \mathrm{nt}$ & $\begin{array}{l}\text { 5B2O and 5B2P } \\
\text { (Hirano et al. } \\
\text { 2016a) }\end{array}$ & Mice zygotes & $\begin{array}{l}\text { Hirano et al. } \\
\text { (2016a) }\end{array}$ \\
\hline $\begin{array}{l}\text { RHA Francisella } \\
\text { novicida Cas9 } \\
\text { variant }\end{array}$ & Class II type II & 1632 & YG & $22 \mathrm{nt}$ & $\begin{array}{r}\text { 5B2Q (Hirano } \\
\text { et al. 2016a) }\end{array}$ & Mice zygotes & $\begin{array}{l}\text { Hirano et al. } \\
\text { (2016a) }\end{array}$ \\
\hline $\begin{array}{l}\text { Treponema denti- } \\
\text { cola } \text { Cas } 9\end{array}$ & Class II type II & 1,423 & NAAAAN & $20 \mathrm{nt}$ & & HEK293T cells & Esvelt et al. (2013) \\
\hline \multirow[t]{7}{*}{$\begin{array}{l}\text { Acidaminococcus } \\
\text { Cas } 12 \mathrm{a}(\mathrm{Cpf} 1)\end{array}$} & \multirow[t]{7}{*}{ Class II type V } & \multirow[t]{7}{*}{$1,308-1,310$} & \multirow[t]{7}{*}{ TTTV } & \multirow[t]{7}{*}{$23,24 \mathrm{nt}$} & \multirow{7}{*}{$\begin{array}{l}\text { 5KK5 (Gao et al. } \\
\text { 2016) } \\
\text { 5B43 (Yamano } \\
\text { et al. 2016) }\end{array}$} & $\begin{array}{l}\text { Human } \\
\text { HEK293FT } \\
\text { cells }\end{array}$ & $\begin{array}{l}\text { Zetsche et al. } \\
\text { (2015a) }\end{array}$ \\
\hline & & & & & & $\begin{array}{l}\text { N2a mouse neuro- } \\
\text { blastoma cells }\end{array}$ & Toth et al. (2016) \\
\hline & & & & & & Mice zygotes & $\begin{array}{l}\text { Watkins-Chow } \\
\text { et al. (2017) }\end{array}$ \\
\hline & & & & & & HEK293T cells & Kim et al. (2016a) \\
\hline & & & & & & HEK293T cells & Kim et al. (2017b) \\
\hline & & & & & & Mice zygotes & Kim et al. (2016b) \\
\hline & & & & & & Mice zygotes & Hur et al. (2016) \\
\hline
\end{tabular}


Table 2 (continued)

\begin{tabular}{|c|c|c|c|c|c|c|c|}
\hline $\begin{array}{l}\text { Species and effec- } \\
\text { tors }\end{array}$ & Class and type & Size (aa) & PAM sequence & Target length & PBD ID & $\begin{array}{l}\text { Cell line/organ- } \\
\text { ism targeted }\end{array}$ & References \\
\hline \multirow[t]{5}{*}{$\begin{array}{l}\text { Lachnospiraceae } \\
\text { Cas12a (Cpf1) }\end{array}$} & \multirow[t]{5}{*}{ Class II type V } & \multirow[t]{5}{*}{1,228} & \multirow[t]{5}{*}{ TTTV } & \multirow[t]{5}{*}{$23,24 \mathrm{nt}$} & \multirow[t]{5}{*}{$\begin{array}{l}\text { 5ID6 (Dong et al. } \\
\text { 2016) }\end{array}$} & $\begin{array}{l}\text { Human } \\
\text { HEK293FT } \\
\text { cells }\end{array}$ & $\begin{array}{l}\text { Zetsche et al. } \\
\text { (2015a) }\end{array}$ \\
\hline & & & & & & $\begin{array}{l}\text { N2a mouse neuro- } \\
\text { blastoma cells }\end{array}$ & Toth et al. (2016) \\
\hline & & & & & & HEK293T cells & Kim et al. (2016a) \\
\hline & & & & & & HEK293T cells & Kim et al. (2017b) \\
\hline & & & & & & Mice zygotes & Kim et al. (2016b) \\
\hline $\begin{array}{l}\text { Leptotrichia } \\
\quad \text { buccalis Cas13a } \\
\quad(\mathrm{C} 2 \mathrm{c} 2)\end{array}$ & class II type VI & 1,159 & N/A & N/A & & $\begin{array}{l}\text { Hela cell } \\
\quad \text { (extracts) }\end{array}$ & $\begin{array}{l}\text { East-Seletsky et al. } \\
\quad(2016)\end{array}$ \\
\hline $\begin{array}{l}\text { Leptotrichia } \\
\text { shahii Cas13a } \\
\text { (C2c2) }\end{array}$ & Class II type VI & 1,389 & N/A & N/A & $\begin{array}{r}\text { 5WTJ and 5WTK } \\
\text { (Liu et al. 2017) }\end{array}$ & E. Coli & $\begin{array}{l}\text { Abudayyeh et al. } \\
\text { (2016) }\end{array}$ \\
\hline $\begin{array}{l}\text { Campylobacter } \\
\text { jejuni Cas9 }\end{array}$ & Class II type II & 984 & $\begin{array}{l}\text { NNNNACAC } \\
\text { or NNNN- } \\
\text { RYAC }\end{array}$ & $22 \mathrm{nt}$ & & $\begin{array}{l}\text { HEK293T cells } \\
\text { Mouse muscle } \\
\text { and retinal pig- } \\
\text { ment epithelium } \\
\text { cells }\end{array}$ & Kim et al. (2017a) \\
\hline
\end{tabular}

N/A - Cas13a enzymes are yet to be applied in mammalian cells and as such, the functional target length and characteristics remains unclear

RNA-guided nucleases may not just provide a solution to the size limitation of using SpCas9 but might also widen the range of potential sequences that can be targeted.

To explore Cas9 orthologues, the sequence databases of bacterial genome sequences can be mined for Cas9-like enzymes. Ran et al., used this approach and screened over 600 Cas 9 sequences and discovered that they cluster into groups of either approximately 1350 amino acids (of which SpCas9 is a member) or a significant shorter 1000 amino acid group (Ran et al. 2015). The following section reviews orthologues with which appreciable activity has been demonstrated in mammalian systems.

\section{Staphylococcus aureus Cas9}

Staphylococcus aureus (SaCas9) was found to have similar levels of gene targeting compared to SpCas9 (Ran et al. 2015). This enzyme targets sequences between 21 and $24 \mathrm{bp}$ in length and requires a 3' NNGRRT PAMs sequence. The shorter size of SaCas9 was compatible with packaging into an all-in-one AAV vector, which was shown to mediate efficient editing in vivo when delivered to mice (Kaminski et al. 2016; Ran et al. 2015). Further highlighting the therapeutic potential of SaCas9, efficient ex vivo genome editing of hematopoietic stem and progenitor cells was demonstrated by AAV delivery (Ye et al. 2016). SaCas9 has also revealed good levels of specificity with some improvement on SpCas9 in a side-by-side comparison (Friedland et al. 2015; Ran et al. 2015). In attempts to further restrict offtarget mutagenesis, the nickase approach has also been applied to $\mathrm{SaCas} 9$, and interestingly the $\mathrm{SaCas} 9$ nickase, along with two sgRNA expression cassettes could be packaged into a single AAV vector (Friedland et al. 2015).

Whether the apparent increase in specificity reported for SaCas9 relates to the requirement for a longer PAM sequence remains to be explored. Clearly, the longer PAM sequence presents some disadvantages as the range of putative target sites would be reduced in comparison with the SpCas9 which recognizes a more simple and thus commonly occurring sequence. Perhaps to address this limitation, the PAM specificities of SaCas9 have also been manipulated by mutagenesis of the SaCas9 and a variant recognizing a NNNRRT PAM motif (variant E782K/ N968K/R1015H, KKH SaCas9) has been reported which shows similar efficiency and specificity as the wild-type SaCas9 (Kleinstiver et al. 2015a). Although SaCas9 is a smaller enzyme than SpCas9 and thus may be more amenable for therapeutic delivery as a single virus, structural analysis of the SaCas9 has also allowed the design of a split-enzyme, which could potentially allow further efficiency improvements for the delivery of this nuclease (Nishimasu et al. 2015).

SaCas9 has also been applied to the fertilized zygote for generating genetically modified mice. Both single and multiplex gene disruptions were demonstrated and the generation of a knock-in modification (Flag tag insertion) was efficiently achieved (Zhang et al. 2016). Similar efficiencies between SaCas9 and SpCas9 were seen in a side-byside comparison at two genomic targets with no difference in mosaicism observed, suggesting similar kinetics and 
activity for both SaCas9 and SpCas9. Mosaicism is a phenomenon described already with SpCas9 (Yen et al. 2014), whereby nuclease activity persists following the first round of cell division leading to allele complexity.

\section{Streptococcus thermophilus Cas9}

Streptococcus thermophilus played a central role in the early history of CRISPR-Cas. It was in this bacterium that CRISPR-Cas9 was first recognized as a prokaryote immune system (Barrangou et al. 2007). Modified for mammalian expression, Streptococcus thermophilus LMD-9 Cas9 encoded by the CRISPR1 locus (St1Cas9) was found to show cleavage activity in mammalian cells (Cong et al. 2013) and was also selected on the basis of showing robust rates of homologous recombination, when compared against two other orthologues from Neisseria meningitides, Treponema denticola and SpCas9 (Esvelt et al. 2013). A direct comparison of St1Cas9 against SpCas9 and SaCas9 in two human loci, however, concluded a lower level of activity (Ran et al. 2015). Interestingly, St1Cas9 was found to require a more complex PAM sequences for activity (Table 2) and the position of cleavage with respect to the PAM was found to be far more heterogeneous than for other orthologues (Ran et al. 2015). St1Cas9 has also been successfully applied in the mouse zygote by microinjection for the generation of genetically modified mice harbouring both indel mutations as well as knock-in alleles (Fujii et al. 2016).

The related Cas9 from the CRISPR3 locus (St3Cas9) was also found to be active in human cells (Xu et al. 2015), and a side-by-side comparison with St1Cas9, St3Cas9 and SpCas9 revealed robust cleavage efficiencies across two genomic loci (Muller et al. 2016). This study also examined off-target mutagenesis and found the two StCas9s to be more accurate than SpCas9. The necessity for more complex PAM sites (NNAGAAW and NGGNG for St1Cas9 and St3Cas9, respectively) potentially contributes to this observation, similar to the observations with SaCas9. Direct delivery of St3Cas9 protein plus crRNA-tracrRNA complex into HEK293T cells was shown to be a reliable strategy for targeting human cells in vitro without the necessity for cloning procedures (Glemzaite et al. 2015).

\section{Neisseria meningitidis Cas9 (NmCas9)}

The Cas9 of Neisseria meningitidis (NmCas9) has been explored as a potential alternative to StCas9, being smaller in length than SpCas9 and with a stringent PAM sequence recognition (5'-NNNNGATT-3') (Table 2) (Zhang et al. 2013; Fonfara et al. 2014). NmCas9 became part of the Cas9 toolbox after studies demonstrated the ability of NmCas9 to induce homologous recombination in human cells (Esvelt et al. 2013; Hou et al. 2013). NmCas9 was found to recognize a 24 nt protospacer, which, together with its more complex PAM, might imply a high level of specificity. Indeed side-by-side comparisons with SpCas9 in human cells revealed lower off-target mutagenesis levels, but also levels of on-target activity were reduced (Lee et al. 2016). Recently an "off-switch" system was found for NmCas9, which provides a means for invading bacteriophages to escape their bacterial host's defence machinery (Pawluk et al. 2016). Three different proteins bind directly to the nuclease, preventing recognition of its target site and thus inhibiting DNA cleavage. These proteins were found to be active against $\mathrm{NmCas} 9$ in human cells, thus providing a method of tempering the activity of the enzyme.

\section{Francisella novicida Cas9 (FnCas9)}

The Cas9 nuclease from Francisella novicida (FnCas9) is one of the largest Cas9 orthologues (1629 amino acids) and demonstrates an interesting feature; In addition to its conventional function as a nuclease in combination with crRNA:tracrRNA, FnCas9 can regulate target mRNA by association with a small CRISPR/Cas-associated RNA (scaRNA):tracrRNA complex (Sampson et al. 2013). This scaRNA, encoded within the Cas cluster, mediates its abrogation of target transcript by a mechanism which is independent of the RuvC and NHN endonuclease domains. The presence of scaRNA-like sequences in Cas gene clusters of several species suggests this non-canonical pathway for Cas9 could be more widespread. Investigations of the FnCas9's nuclease function with substrates in vitro revealed specificity for an NGG PAM sequence (Hirano et al. 2016a). Interestingly, when applied in mammalian cells, no evidence of indel formation could be found. However, microinjection of mouse zygotes with FnCas9 as a ribonucleoprotein complex, led to highly efficient site-specific indel formation (Hirano et al. 2016a). Similar to previous work with SpCas9, structural information has facilitated its mutagenesis to generate a functional variant FnCas9 that recognizes an alternative 5'-YG-3' PAM (E1369R/E1449H/ R1556A substitutions, RHA FnCas9 variant), thus expanding the target space for this nuclease (Hirano et al. 2016a).

\section{Campylobacter jejuni Cas9 (CjCas9)}

A new Cas9 orthologue derived from Campylobacter jejuni (CjCas9) was used successfully for genome editing in mammalian cells in vitro and in vivo (Kim et al. 2017a). Being one of the smallest Cas9 orthologues (984 amino acids, Fig. 2), a GFP-tagged CjCas9 was able to be packaged together with a expression cassette for its sgRNA in a single AAV vector and administrated to mice. Efficient indel mutagenesis was observed at the target loci in both 
muscle and the retina, suggesting potential therapeutic application of this Cas9 orthologue could be feasible. Kim et al. (2017a) also determined that CjCas9 recognizes a 22-nucleotide target sequence upstream of the PAM motifs 5'-NNNNACAC-3' or 5'-NNNNRYAC-3'. A direct comparison of cutting efficiencies and off-target mutagenesis revealed that CjCas9 showed similar cutting efficiencies to SpCas9 and SaCas9, but CjCas9 was found to be more specific than $\mathrm{SpCas} 9$ and $\mathrm{SaCas} 9$ at a number of different target sites.

The study of the CjCas9 crystal structure in complex with an sgRNA and its target DNA complex reveals new insights into the function of this Cas9 orthologue. CjCas9, unlike other cas9 orthologues, bound both the target and non-target DNA strand (Yamada et al. 2017). Furthermore, the structure of the crRNA:tracrRNA was found to be substantially different to other Cas9 orthologues with the tracrRNA containing a triple-helix structure. These observations reveal once again the mechanistic diversity of the CRISPR-Cas9 systems.

\section{Cas12a (Cpf1)}

The discovery of an additional class 2 CRISPR effector, originally described as Cpf1 and now reclassified as Cas12a (Shmakov et al. 2017), was received with great interest, mainly because the protein is structurally distinct from Cas9 effectors and possesses new interesting traits. Firstly, Cas12a binds to its target sequence by its association with a single RNA species, without the requirement of an additional tracrRNA (Zetsche et al. 2015a). Secondly, the Cas12a-crRNA complex recognizes a T-rich PAM sequence, lying $5^{\prime}$ of its target sequence (Fonfara et al. 2016; Yamano et al. 2016; Zetsche et al. 2015a), in contrast to the G-rich PAM sequence of the Cas9 systems that lies $3^{\prime}$ of its target. The T-rich PAM is of note as it might facilitate genome engineering in organisms with particularly AT-rich genomes. The PAM motif was initially reported as being TTTN; however, recent more in depth investigations in mammalian cells have revealed that target sequences with a TTTT PAM motif are inefficiently cleaved and this study redefined the Cas12a PAM as being TTTV (Kim et al. 2017b). Thirdly, Cas12a cleaves DNA via a staggered DSB, leaving a 4 or 5-nt 5' overhang (Fonfara et al. 2016; Zetsche et al. 2015a), an attribute which might facilitate the introduction of specific sequences into the genome. Moreover, the staggered cleavage site of Cas12a from Francisella novicida U112 occurs after the 18th base on the non-targeted (+) strand and after the 23rd base on the targeted (-) strand, which is quite distant from the PAM sequence (Zetsche et al. 2015a). This distal cleavage, far away from both the seed region and the PAM, might preserve the target sequence for subsequent rounds of cleavage. This might be useful for encouraging repair via HDR for the targeted integration of exogenous DNA, since indel mutations caused by the dominant NHEJ repair pathway would be less likely to destroy the target site. Cas12a, orthologues of which have been identified in several bacterial and archeal genomes (Makarova et al. 2015), contains only a RuvC-like endonuclease domain and lacks the $\mathrm{HNH}$ domain present in Cas9 proteins. A putative novel nuclease domain, Nuc domain, has been ascertained from the crystal structure, which provides the 2nd nuclease activity responsible for cleaving the target strand (Yamano et al. 2016). Furthermore, a ribonuclease activity has been ascribed to this enzyme and has a role in processing of the precursor CRISPR RNA (Fonfara et al. 2016).

Screening of Cas12a-family enzymes from diverse bacteria identified two candidates from Acidaminococcus sp. BV3L6 (AsCas12a) and Lachnospiraceae bacterium ND2006 (LbCas12a) that are capable of mediating genome editing in human cells (Kim et al. 2016a; Zetsche et al. 2015a). Side-by-side comparisons of activity by measuring indel formation (Kim et al. 2016a) or assessing rates of homology directed repair efficiencies (Toth et al. 2016) revealed, in general, a lower activity for Cas12a orthologues when compared to SpCas9. However, the genomewide analysis of cleavage sites in vitro for LbCas12a and AsCas12a showed that fewer off-target events were reported in comparison with Cas9 nucleases. Indeed, crystal structures of Cas12a-crRNA complexed with its DNA target reveal a unique mechanism for target recognition that is quite distinct from that reported for Cas9, which perhaps contributes to the increased specificity (Gao et al. 2016). However, it should be determined whether this increased specificity simply results from the smaller number of TTTV sites, the preferred PAM motif, in the mammalian genome or from the Cas12a system per se.

The potential of Cas12a for targeted mutagenesis in whole organisms was demonstrated by successful production of mutant mice by delivering AsCas 12a and LbCas12a to the zygote by electroporation (Hur et al. 2016) and microinjection (Kim et al. 2016b; Watkins-Chow et al. 2017). Investigations of off-target mutagenesis by deep sequencing in the resulting mutant mice confirmed the high fidelity of Cas12a, with no mutations found at homologous sites (Hur et al. 2016; Kim et al. 2016b). On the other hand, a high level of mosaicism was observed in live pups after AsCas12a microinjection (Watkins-Chow et al. 2017).

\section{Cas13a (C2C2)}

Further class 2 type CRISPR effectors have been mined from bacterial sequence databases using sophisticated 
computational pipelines, using the Cas1 sequence as an anchor to identify candidate loci (Shmakov et al. 2015). Using this strategy, two RuvC containing proteins distantly related to Cas12a (Cpf1), C2c1, now known as Cas12b, and $\mathrm{C} 2 \mathrm{c} 3$, now known as Cas $12 \mathrm{c}$, were identified and were found to be present in diverse bacterial genomes. An additional protein family, originally named $\mathrm{C} 2 \mathrm{c} 2$ and now classified as Cas13a (Shmakov et al. 2017), was identified (Shmakov et al. 2015) which, as confirmed by recent structural studies (Liu et al. 2017), contains 2 HEPN RNase domains, suggesting its target molecule could be an RNA. Expression of both Cas13a from Leptotrichia shahii (LsCas13a) and a crRNA against a target within the MS2 ssRNA bacteriophage in E. coli protected the bacteria from infection (Abudayyeh et al. 2016), confirming the minimal requirements for an operational RNA-guided site-specific RNAse.

Cas13a is directed to its target RNA by a single crRNA, similar to Cas12a and has preference for sequence with $\mathrm{C}$, A and $\mathrm{U}$ immediately flanking the $3^{\prime}$ end of the protospacer. For activity in vitro, the crRNA requires target homology and is also dependent upon the secondary structure of the crRNA direct repeat stem. Surprisingly, in addition to the cleavage of the target RNA, it was found that LsCas13a, once activated, gains a non-specific RNAse activity and thus cleaves collateral RNA, ultimately leading to programmed cell death or senescence.

Although not yet applied in mammalian cells, functionality of the system was demonstrated for Leptotrichia buccalis Cas13a (LbCas13a) in Hela cell extracts (East-Seletsky et al. 2016). In this study, the non-specific RNAse activity of the activated enzyme was used to signal the presence of a specific target RNA in a population that activated the enzyme. Thus, although the promiscuous cleavage of RNAs might limit its use as a specific tool for ablating specific RNAs, this effector looks set to become a useful biotechnological tool for detecting specific RNAs, as has recently been demonstrated (Gootenberg et al. 2017). A greater understanding of how these RNAse activities work in consort to achieve site-specific cleavage of target RNAs may facilitate the application of this enzyme class as an experimental tool to ablate specific RNA transcripts in the absence of genomic cleavage. In addition, a catalytically inert Cas13a could be a useful device for the localization and imaging of RNA populations within the cell.

\section{Summary}

In the few years since the discovery of SpCas9 and its first application in mammalian cells, we now have a wealth of enzymes with a range of activities and specificities. Mining the bacterial sequence databases has been lucrative and has provided a variety of novel enzymes. Where nature cannot provide the diversity of function needed, structural studies driving mutagenesis of the enzymes provides a means of tailoring specific characteristics to increase fidelity or broaden target range. It is hoped that the diversity of functions, which all these orthologues and variants provide, will facilitate therapeutic applications of these site-specific nucleases. As well as nucleases, these molecules can serve as effective DNA-binding domains, tethering machinery for visualizing specific loci or modulating gene expression (Dominguez et al. 2016). Indeed, engineered orthologues have already been used for both gene activation (Nishimasu et al. 2015) and for fluorescent labelling of genomic loci (Chen et al. 2016; Ma et al. 2015). The use of different deactivated CRISPR effectors recognizing varied sequences on DNA and even RNA will open up new possibilities for interrogating the genome and for future therapeutics.

Acknowledgements Support for this work was received from the Wellcome Trust (203141/Z/16/Z).

Open Access This article is distributed under the terms of the Creative Commons Attribution 4.0 International License (http:// creativecommons.org/licenses/by/4.0/), which permits unrestricted use, distribution, and reproduction in any medium, provided you give appropriate credit to the original author(s) and the source, provide a link to the Creative Commons license, and indicate if changes were made.

\section{References}

Abudayyeh OO, Gootenberg JS, Konermann S, Joung J, Slaymaker IM, Cox DB, Shmakov S, Makarova KS, Semenova E, Minakhin L, Severinov K, Regev A, Lander ES, Koonin $\mathrm{EV}$, Zhang F (2016) C2c2 is a single-component programmable RNA-guided RNA-targeting CRISPR effector. Science 353:aaf5573

Anders C, Niewoehner O, Duerst A, Jinek M (2014) Structural basis of PAM-dependent target DNA recognition by the Cas9 endonuclease. Nature 513:569-573

Anders C, Bargsten K, Jinek M (2016) Structural plasticity of PAM recognition by engineered variants of the RNA-guided endonuclease Cas9. Mol Cell 61:895-902

Aouida M, Eid A, Ali Z, Cradick T, Lee C, Deshmukh H, Atef A, AbuSamra D, Gadhoum SZ, Merzaban J, Bao G, Mahfouz M (2015) Efficient fdCas9 synthetic endonuclease with improved specificity for precise genome engineering. PLoS ONE 10:e0133373

Barrangou R, Fremaux C, Deveau H, Richards M, Boyaval P, Moineau S, Romero DA, Horvath P (2007) CRISPR provides acquired resistance against viruses in prokaryotes. Science 315:1709-1712

Bétermier M, Bertrand P, Lopez BS (2014) Is non-homologous endjoining really aninherently error-prone process? PLoS Genet 10:e1004086

Bialk P, Rivera-Torres N, Strouse B, Kmiec EB (2015) Regulation of gene editing activity directed by single-stranded oligonucleotides and CRISPR/Cas9 systems. PLoS ONE 10:e0129308 
Bolukbasi MF, Gupta A, Oikemus S, Derr AG, Garber M, Brodsky MH, Zhu LJ, Wolfe SA (2015) DNA-binding-domain fusions enhance the targeting range and precision of Cas9. Nat Methods 12(12):1150-1156

Chen B, Hu J, Almeida R, Liu H, Balakrishnan S, Covill-Cooke C, Lim WA, Huang B (2016) Expanding the CRISPR imaging toolset with Staphylococcus aureus Cas9 for simultaneous imaging of multiple genomic loci. Nucleic Acids Res 44:e75-e75

Cho SW, Kim S, Kim JM, Kim JS (2013) Targeted genome engineering in human cells with the Cas9 RNA-guided endonuclease. Nat Biotechnol 31(3):230-232

Cho SW, Kim S, Kim Y, Kweon J, Kim HS, Bae S, Kim J-S (2014) Analysis of off-target effects of CRISPR/Cas-derived RNAguided endonucleases and nickases. Genome Res 24:132-141

Chu VT, Weber T, Graf R, Sommermann T, Petsch K, Sack U, Volchkov P, Rajewsky K, Kühn R (2016) Efficient generation of Rosa26 knock-in mice using CRISPR/Cas9 in C57BL/6 zygotes. BMC Biotechnol 16:4

Cong L, Ran FA, Cox D, Lin S, Barretto R, Habib N, Hsu PD, Wu X, Jiang W, Marraffini LA, Zhang F (2013) Multiplex Genome engineering using CRISPR/Cas systems. Science 339:819-823

Cradick TJ, Fine EJ, Antico CJ, Bao G (2013) CRISPR/Cas9 systems targeting $\beta$-globin and CCR5 genes have substantial off-target activity. Nucleic Acids Res 41:9584-9592

Davis L, Maizels N (2014) Homology-directed repair of DNA nicks via pathways distinct from canonical double-strand break repair. Proc Natl Acad Sci USA 111(10):E924-E932

Deltcheva E, Chylinski K, Sharma CM, Gonzales K, Chao Y, Pirzada ZA, Eckert MR, Vogel J, Charpentier E (2011) CRISPR RNA maturation by trans-encoded small RNA and host factor RNase III. Nature 471(7340):602-607

Dianov GL, Hübscher U (2013) Mammalian base excision repair: the forgotten archangel. Nucleic Acids Res 41:3483-3490

Dominguez AA, Lim WA, Qi LS (2016) Beyond editing: repurposing CRISPR-Cas9 for precision genome regulation and interrogation. Nat Rev Mol Cell Biol 17:5-15

Dong D, Ren K, Qiu X, Zheng J, Guo M, Guan X, Liu H, Li N, Zhang B, Yang D, Ma C, Wang S, Wu D, Ma Y, Fan S, Wang J, Gao N, Huang Z (2016) The crystal structure of Cpf1 in complex with CRISPR RNA. Nature 532:522-526

East-Seletsky A, O'Connell MR, Knight SC, Burstein D, Cate JH, Tjian R, Doudna JA (2016) Two distinct RNase activities of CRISPR-C2c2 enable guide-RNA processing and RNA detection. Nature 538:270-273

Eggenschwiler R, Moslem M, Fráguas MS, Galla M, Papp O, Naujock M, Fonfara I, Gensch I, Wähner A, Beh-Pajooh A, Mussolino C, Tauscher M, Steinemann D, Wegner F, Petri S, Schambach A, Charpentier E, Cathomen T, Cantz T (2016) Improved biallelic modification of a transcriptionally silent locus in patientderived iPSC by Cas9 nickase. Sci Rep 6:38198

Esvelt KM, Mali P, Braff JL, Moosburner M, Yaung SJ, Church GM (2013) Orthogonal Cas9 proteins for RNA-guided gene regulation and editing. Nat Methods 10:1116-1121

Fonfara I, Le Rhun A, Chylinski K, Makarova KS, Lecrivain AL, Bzdrenga J, Koonin EV, Charpentier E (2014) Phylogeny of Cas9 determines functional exchangeability of dual-RNA and Cas9 among orthologous type II CRISPR-Cas systems. Nucleic Acids Res 42:2577-2590

Fonfara I, Richter H, Bratovic M, Le Rhun A, Charpentier E (2016) The CRISPR-associated DNA-cleaving enzyme Cpf1 also processes precursor CRISPR RNA. Nature 532:517-521

Friedland AE, Baral R, Singhal P, Loveluck K, Shen S, Sanchez M, Marco E, Gotta GM, Maeder ML, Kennedy EM, Kornepati AV, Sousa A, Collins MA, Jayaram H, Cullen BR, Bumcrot D (2015) Characterization of Staphylococcus aureus Cas9: a smaller Cas9 for all-in-one adeno-associated virus delivery and paired nickase applications. Genome Biol 16:257

Fu Y, Foden JA, Khayter C, Maeder ML, Reyon D, Joung JK, Sander JD (2013) High-frequency off-target mutagenesis induced by CRISPR-Cas nucleases in human cells. Nat Biotechnol 31:822-826

Fu Y, Sander JD, Reyon D, Cascio VM, Joung JK (2014) Improving CRISPR-Cas nuclease specificity using truncated guide RNAs. Nat Biotechnol 32(3):279-284

Fujii W, Kakuta S, Yoshioka S, Kyuwa S, Sugiura K, Naito K (2016) Zygote-mediated generation of genome-modified mice using Streptococcus thermophilus 1-derived CRISPR/Cas system. Biochem Biophys Res Commun 477:473-476

Gao P, Yang H, Rajashankar KR, Huang Z, Patel DJ (2016) Type V CRISPR-Cas Cpf1 endonuclease employs a unique mechanism for crRNA-mediated target DNA recognition. Cell Res 26:901-913

Gasiunas G, Barrangou R, Horvath P, Siksnys V (2012) Cas9crRNA ribonucleoprotein complex mediates specific DNA cleavage for adaptive immunity in bacteria. Proc Natl Acad Sci USA 109:E2579-E2586

Ghezraoui H, Piganeau M, Renouf B, Renaud J-B, Sallmyr A, Ruis B, Oh S, Tomkinson AE, Hendrickson Eric A, Giovannangeli C, Jasin M, Brunet E (2014) Chromosomal translocations in human cells are generated by canonical nonhomologous endjoining. Mol Cell 55:829-842

Glemzaite M, Balciunaite E, Karvelis T, Gasiunas G, Grusyte MM, Alzbutas G, Jurcyte A, Anderson EM, Maksimova E, Smith AJ, Lubys A, Zaliauskiene L, Siksnys V (2015) Targeted gene editing by transfection of in vitro reconstituted Streptococcus thermophilus Cas9 nuclease complex. RNA Biol 12:1-4

Gootenberg JS, Abudayyeh OO, Lee JW, Essletzbichler P, Dy AJ, Joung J, Verdine V, Donghia N, Daringer NM, Freije CA, Myhrvold C, Bhattacharyya RP, Livny J, Regev A, Koonin EV, Hung DT, Sabeti PC, Collins JJ, Zhang F (2017) Nucleic acid detection with CRISPR-Cas13a/C2c2. Science. doi:10.1126/science.aam9321

Greene EC (2016) DNA sequence alignment during homologous recombination. J Biol Chem 291:11572-11580

Guilinger JP, Thompson DB, Liu DR (2014) Fusion of catalytically inactive Cas9 to FokI nuclease improves the specificity of genome modification. Nat Biotechnol 32:577-582

Hara S, Tamano M, Yamashita S, Kato T, Saito T, Sakuma T, Yamamoto T, Inui M, Takada S (2015) Generation of mutant mice via the CRISPR/Cas9 system using FokI-dCas9. Sci Rep $5: 11221$

Hirano H, Gootenberg JS, Horii T, Abudayyeh OO, Kimura M, Hsu PD, Nakane T, Ishitani R, Hatada I, Zhang F, Nishimasu H, Nureki O (2016a) Structure and engineering of Francisella novicida Cas9. Cell 164:950-961

Hirano S, Nishimasu H, Ishitani R, Nureki O (2016b) Structural basis for the altered PAM specificities of engineered CRISPR-Cas9. Mol Cell 61:886-894

Hou Z, Zhang Y, Propson NE, Howden SE, Chu LF, Sontheimer EJ, Thomson JA (2013) Efficient genome engineering in human pluripotent stem cells using Cas9 from Neisseria meningitidis. Proc Natl Acad Sci USA 110:15644-15649

Hur JK, Kim K, Been KW, Baek G, Ye S, Hur JW, Ryu SM, Lee YS, Kim JS (2016) Targeted mutagenesis in mice by electroporation of Cpf1 ribonucleoproteins. Nat Biotechnol 34:807-808

Iyer V, Shen B, Zhang W, Hodgkins A, Keane T, Huang X, Skarnes WC (2015) Off-target mutations are rare in Cas9-modified mice. Nat Methods 12(6):479

Jiang F, Zhou K, Ma L, Gressel S, Doudna JA (2015) A Cas9-guide RNA complex preorganized for target DNA recognition. Science 348:1477-1481 
Jiang F, Taylor DW, Chen JS, Kornfeld JE, Zhou K, Thompson AJ, Nogales E, Doudna JA (2016) Structures of a CRISPRCas9 R-loop complex primed for DNA cleavage. Science 351:867-871

Jinek M, Chylinski K, Fonfara I, Hauer M, Doudna JA, Charpentier E (2012) A programmable dual-RNA-guided DNA endonuclease in adaptive bacterial immunity. Science 337:816-821

Jinek M, East A, Cheng A, Lin S, Ma E, Doudna J (2013) RNAprogrammed genome editing in human cells. Elife 2:e00471

Jinek M, Jiang F, Taylor DW, Sternberg SH, Kaya E, Ma E, Anders C, Hauer M, Zhou K, Lin S, Kaplan M, Iavarone AT, Charpentier E, Nogales E, Doudna JA (2014) Structures of Cas9 endonucleases reveal RNA-mediated conformational activation. Science 343(6176): 1247997

Kaminski R, Bella R, Yin C, Otte J, Ferrante P, Gendelman HE, Li H, Booze R, Gordon J, Hu W, Khalili K (2016) Excision of HIV-1 DNA by gene editing: a proof-of-concept in vivo study. Gene Ther 23:690-695

Kim S, Kim D, Cho SW, Kim J, Kim JS (2014) Highly efficient RNA-guided genome editing in human cells via delivery of purified Cas9 ribonucleoproteins. Genome Res 24(6):1012-1019

Kim D, Bae S, Park J, Kim E, Kim S, Yu HR, Hwang J, Kim JI, Kim JS (2015) Digenome-seq: genome-wide profiling of CRISPR-Cas9 off-target effects in human cells. Nat Methods 12(3):237-243

Kim D, Kim J, Hur JK, Been KW, Yoon SH, Kim JS (2016a) Genome-wide analysis reveals specificities of Cpf1 endonucleases in human cells. Nat Biotechnol 34:863-868

Kim Y, Cheong SA, Lee JG, Lee SW, Lee MS, Baek IJ, Sung YH (2016b) Generation of knockout mice by Cpf1-mediated gene targeting. Nat Biotechnol 34:808-810

Kim E, Koo T, Park SW, Kim D, Kim K, Cho HY, Song DW, Lee KJ, Jung MH, Kim S, Kim JH, Kim JH, Kim JS (2017a) In vivo genome editing with a small Cas9 orthologue derived from Campylobacter jejuni. Nat Commun. doi:10.1038/ ncomms 14500

Kim HK, Song M, Lee J, Menon AV, Jung S, Kang YM, Choi JW, Woo E, Koh HC, Nam JW, Kim H (2017b) In vivo highthroughput profiling of CRISPR-Cpf1 activity. Nat Methods 14(2):153-159

Kleinstiver BP, Prew MS, Tsai SQ, Nguyen NT, Topkar VV, Zheng ZL, Joung JK (2015a) Broadening the targeting range of Staphylococcus aureus CRISPR-Cas9 by modifying PAM recognition. Nat Biotechnol 33(12):1293-1298

Kleinstiver BP, Prew MS, Tsai SQ, Topkar VV, Nguyen NT, Zheng Z, Gonzales APW, Li Z, Peterson RT, Yeh J-RJ, Aryee MJ, Joung JK (2015b) Engineered CRISPR-Cas9 nucleases with altered PAM specificities. Nature 523:481-485

Kleinstiver BP, Pattanayak V, Prew MS, Tsai SQ, Nguyen NT, Zheng Z, Joung JK (2016) High-fidelity CRISPR-Cas9 nucleases with no detectable genome-wide off-target effects. Nature 529:490-495

Lee AY-f, Lloyd KCK (2014) Conditional targeting of Ispd using paired Cas9 nickase and a single DNA template in mice. FEBS Open Bio 4:637-642

Lee CM, Cradick TJ, Bao G (2016) The Neisseria meningitidis CRISPR-Cas9 system enables specific genome editing in mammalian cells. Mol Ther 24:645-654

Lieber MR (2010) The mechanism of double-strand DNA break repair by the nonhomologous DNA end-joining pathway. Annu Rev Biochem 79:181-211

Liu L, Li X, Wang J, Wang M, Chen P, Yin M, Li J, Sheng G, Wang Y (2017) Two distant catalytic sites are responsible for C2c2 RNase activities. Cell 168:121-134.e112
Ma H, Naseri A, Reyes-Gutierrez P, Wolfe SA, Zhang S, Pederson T (2015) Multicolor CRISPR labeling of chromosomal loci in human cells. Proc Natl Acad Sci 112:3002-3007

Makarova KS, Wolf YI, Alkhnbashi OS, Costa F, Shah SA, Saunders SJ, Barrangou R, Brouns SJJ, Charpentier E, Haft DH, Horvath P, Moineau S, Mojica FJM, Terns RM, Terns MP, White MF, Yakunin AF, Garrett RA, van der Oost J, Backofen R, Koonin EV (2015) An updated evolutionary classification of CRISPRCas systems. Nat Rev Micro 13:722-736

Mali P, Yang L, Esvelt KM, Aach J, Guell M, DiCarlo JE, Norville JE, Church GM (2013a) RNA-guided human genome engineering via Cas9. Science 339:823-826

Mali P, Aach J, Stranges PB, Esvelt KM, Moosburner M, Kosuri S, Yang L, Church GM (2013b) CAS9 transcriptional activators for target specificity screening and paired nickases for cooperative genome engineering. Nat Biotechnol 31:833-838

Mianné J, Chessum L, Kumar S, Aguilar C, Codner G, Hutchison M, Parker A, Mallon A-M, Wells S, Simon MM, Teboul L, Brown SDM, Bowl MR (2016) Correction of the auditory phenotype in C57BL/6 N mice via CRISPR/Cas9-mediated homology directed repair. Genome Med 8:16

Miyaoka Y, Berman JR, Cooper SB, Mayerl SJ, Chan AH, Zhang B, Karlin-Neumann GA, Conklin BR (2016) Systematic quantification of HDR and NHEJ reveals effects of locus, nuclease, and cell type on genome-editing. Sci Rep 6:23549

Muller M, Lee CM, Gasiunas G, Davis TH, Cradick TJ, Siksnys V, Bao G, Cathomen T, Mussolino C (2016) Streptococcus thermophilus CRISPR-Cas9 systems enable specific editing of the human genome. Mol Ther 24:636-644

Naldini L (2015) Gene therapy returns to centre stage. Nature 526:351-360

Nishimasu H, Ran FA, Hsu PD, Konermann S, Shehata SI, Dohmae N, Ishitani R, Zhang F, Nureki O (2014) Crystal structure of Cas9 in complex with guide RNA and target DNA. Cell 156:935-949

Nishimasu H, Cong L, Yan WX, Ran FA, Zetsche B, Li Y, Kurabayashi A, Ishitani R, Zhang F, Nureki O (2015) Crystal structure of Staphylococcus aureus Cas9. Cell 162:1113-1126

Osborn MJ, Gabriel R, Webber BR, DeFeo AP, McElroy AN, Jarjour J, Starker CG, Wagner JE, Joung JK, Voytas DF, von Kalle C, Schmidt M, Blazar BR, Tolar J (2015) Fanconi anemia gene editing by the CRISPR/Cas9 system. Hum Gene Ther 26:114-126

Pan Y, Shen N, Jung-Klawitter S, Betzen C, Hoffmann GF, Hoheisel JD, Blau N (2016) CRISPR RNA-guided FokI nucleases repair a PAH variant in a phenylketonuria model. Sci Rep 6:35794

Pawluk A, Amrani N, Zhang Y, Garcia B, Hidalgo-Reyes Y, Lee J, Edraki A, Shah M, Sontheimer EJ, Maxwell KL, Davidson AR (2016) Naturally occurring off-switches for CRISPR-Cas9. Cell 167(1829-1838):e1829

Ran FA, Hsu PD, Lin C-Y, Gootenberg JS, Konermann S, Trevino A, Scott DA, Inoue A, Matoba S, Zhang Y, Zhang F (2013) Double nicking by RNA-guided CRISPR Cas9 for enhanced genome editing specificity. Cell 154:1380-1389

Ran FA, Cong L, Yan WX, Scott DA, Gootenberg JS, Kriz AJ, Zetsche B, Shalem O, Wu X, Makarova KS, Koonin EV, Sharp PA, Zhang F (2015) In vivo genome editing using Staphylococcus aureus Cas9. Nature 520:186-191

Richardson CD, Ray GJ, DeWitt MA, Curie GL, Corn JE (2016) Enhancing homology-directed genome editing by catalytically active and inactive CRISPR-Cas9 using asymmetric donor DNA. Nat Biotechnol 34:339-344

Sakuma T, Masaki K, Abe-Chayama H, Mochida K, Yamamoto T, Chayama K (2016) Highly multiplexed CRISPR-Cas9-nuclease and Cas9-nickase vectors for inactivation of hepatitis B virus. Genes Cells 21:1253-1262 
Sampson TR, Saroj SD, Llewellyn AC, Tzeng YL, Weiss DS (2013) A CRISPR/Cas system mediates bacterial innate immune evasion and virulence. Nature 497:254-257

Sander JD, Joung JK (2014) CRISPR-Cas systems for editing, regulating and targeting genomes. Nat Biotechnol 32:347-355

Shen B, Zhang W, Zhang J, Zhou J, Wang J, Chen L (2014) Efficient genome modification by CRISPR-Cas 9 nickase with minimal off-target effects. Nat Methods 11:399-402

Shmakov S, Abudayyeh OO, Makarova KS, Wolf YI, Gootenberg JS, Semenova E, Minakhin L, Joung J, Konermann S, Severinov K, Zhang F, Koonin EV (2015) Discovery and functional characterization of diverse class 2 CRISPR-Cas systems. Mol Cell 60:385-397

Shmakov S, Smargon A, Scott D, Cox D, Pyzocha N, Yan W, Abudayyeh OO, Gootenberg JS, Makarova KS, Wolf YI, Severinov K, Zhang F, Koonin EV (2017) Diversity and evolution of class 2 CRISPR-Cas systems. Nat Rev Microbiol 15(3):169-182

Sinha S, Li F, Villarreal D, Shim JH, Yoon S, Myung K, Shim EY, Lee SE (2017) Microhomology-mediated end joining induces hypermutagenesis at breakpoint junctions. PLos Genet 13(4):e1006714

Slaymaker IM, Gao L, Zetsche B, Scott DA, Yan WX, Zhang F (2016) Rationally engineered Cas9 nucleases with improved specificity. Science 351:84-88

Terao M, Tamano M, Hara S, Kato T, Kinoshita M, Takada S (2016) Utilization of the CRISPR/Cas9 system for the efficient production of mutant mice using crRNA/tracrRNA with Cas9 nickase and FokI-dCas9. Exp Anim 65:275-283

Toth E, Weinhardt N, Bencsura P, Huszar K, Kulcsar PI, Talas A, Fodor E, Welker E (2016) Cpf1 nucleases demonstrate robust activity to induce DNA modification by exploiting homology directed repair pathways in mammalian cells. Biol Direct 11:46

Truong D-JJ, Kühner K, Kühn R, Werfel S, Engelhardt S, Wurst W, Ortiz O (2015) Development of an intein-mediated split-Cas9 system for gene therapy. Nucleic Acids Res 43:6450-6458

Tsai SQ, Wyvekens N, Khayter C, Foden JA, Thapar V, Reyon D, Goodwin MJ, Aryee MJ, Joung JK (2014) Dimeric CRISPR RNA-guided FokI nucleases for highly specific genome editing. Nat Biotechnol 32:569-576

Watkins-Chow DE, Varshney GK, Garrett LJ, Chen Z, Jimenez EA, Rivas C, Bishop KS, Sood R, Harper UL, Pavan WJ, Burgess SM (2017) Highly-efficient Cpf1-mediated gene targeting in mice following high concentration pronuclear injection. G3 (Bethesda) 7(2):719-722

Wright AV, Sternberg SH, Taylor DW, Staahl BT, Bardales JA, Kornfeld JE, Doudna JA (2015) Rational design of a split-Cas9 enzyme complex. Proc Natl Acad Sci USA 112:2984-2989
Wu J, Hunt SD, Xue H, Liu Y, Darabi R (2016) Generation and validation of PAX7 reporter lines from human iPS cells using CRISPR/Cas9 technology. Stem Cell Res 16:220-228

Xu K, Ren C, Liu Z, Zhang T, Zhang T, Li D, Wang L, Yan Q, Guo L, Shen J, Zhang Z (2015) Efficient genome engineering in eukaryotes using Cas9 from Streptococcus thermophilus. Cell Mol Life Sci 72:383-399

Yamada M, Watanabe Y, Gootenberg JS, Hirano H, Ran FA, Nakane T, Ishitani R, Zhang F, Nishimasu H, Nureki O (2017) Crysal structure of the minimal Cas9 from Campylobacter jejuni reveals the molecular diversity in the CRISPR-Cas9 systems. Mol Cell 65:1109-1121

Yamano T, Nishimasu H, Zetsche B, Hirano H, Slaymaker IM, Li Y, Fedorova I, Nakane T, Makarova KS, Koonin EV, Ishitani R, Zhang F, Nureki O (2016) Crystal structure of Cpf1 in complex with guide RNA and target DNA. Cell 165:949-962

Ye L, Wang J, Tan Y, Beyer AI, Xie F, Muench MO, Kan YW (2016) Genome editing using CRISPR-Cas9 to create the HPFH genotype in HSPCs: an approach for treating sickle cell disease and beta-thalassemia. Proc Natl Acad Sci USA 113:10661-10665

Yen S-T, Zhang M, Deng JM, Usman SJ, Smith CN, Parker-Thornburg J, Swinton PG, Martin JF, Behringer RR (2014) Somatic mosaicism and allele complexity induced by CRISPR/Cas9 RNA injections in mouse zygotes. Dev Biol 393:3-9

Zetsche B, Gootenberg JS, Abudayyeh OO, Slaymaker IM, Makarova KS, Essletzbichler P, Volz SE, Joung J, van der Oost J, Regev A, Koonin EV, Zhang F (2015a) Cpf1 is a single RNAguided endonuclease of a class 2 CRISPR-Cas system. Cell 163:759-771

Zetsche B, Volz SE, Zhang F (2015b) A split-Cas9 architecture for inducible genome editing and transcription modulation. Nat Biotechnol 33:139-142

Zhang Y, Heidrich N, Ampattu BJ, Gunderson CW, Seifert HS, Schoen C, Vogel J, Sontheimer EJ (2013) Processing-independent CRISPR RNAs limit natural transformation in Neisseria meningitidis. Mol Cell 50(4):488-503

Zhang Y, Ge X, Yang F, Zhang L, Zheng J, Tan X, Jin Z-B, Qu J, Gu F (2014) Comparison of non-canonical PAMs for CRISPR/ Cas9-mediated DNA cleavage in human cells. Sci Rep 4:5405

Zhang X, Liang P, Ding C, Zhang Z, Zhou J, Xie X, Huang R, Sun Y, Sun H, Zhang J, Xu Y, Songyang Z, Huang J (2016) Efficient production of gene-modified mice using Staphylococcus aureus Cas9. Sci Rep 6:32565 